\title{
Starting up a Physician's Practice
}

\section{Ecler Jaqua, MD, DipABLM, DipABOM, FAAFP 1, ", Terry Jaqua, PhDc, MBA ${ }^{2}$}

${ }^{1}$ Loma Linda University Health. Family Medicine Department, USA

${ }^{2}$ Trident University International, Health Sciences Program, USA

*Corresponding Author: Ecler Jaqua, Loma Linda University Health. Family Medicine Department, USA

Received date: 26 April 2021; Accepted date: 05 May 2021; Published date: 07 May 2021

Citation: Jaqua E, Jaqua T. Starting up a Physician's Practice. J Comm Med and Pub Health Rep 2(3): https://doi.org/10.38207/jcmphr20210040

Copyright: (C) 2021 Ecler Jaqua. This is an open-access article distributed under the terms of the Creative Commons Attribution License, which permits unrestricted use, distribution, and reproduction in any medium, provided the original author and source are credited.

Physicians play an essential part in the health care industry. They act as both the patient's health care consultant and medical service provider, acting on behalf of the patient to choose medical services. However, they also organize into firms and can thus serve as profitmaximizing agents. Consequently, by stretching their bargaining muscles by joining firms, physicians can increase the service fees they charge insurance carriers. This paper will discuss the composition of the physician practice market in my hometown, its concentration, and its structure nationwide.

\section{Structure of the Physician Practice Market in a Local Hometown}

In essence, the physician services market in my hometown is a monopoly. The reason behind this situation is that the citizens perceive medical services as an inhomogeneous good; thus, physicians have a form of monopolistic power in the supply of their services. Second, similar to monopolistic competition in other industries, information asymmetry between physicians and patients in my hometown. Physicians are better-informed about diseases and treatments than patients. Accordingly, the patients' demands for services are determined by the recommendations of the physicians. Similarly, this incomplete information on the part of patients is a cause of the apparent

\section{The Concentration of the Physician Practice Market}

In the United States, the physician services industry is relatively saturated since 2010, with market size of about $\$ 229$ bn (IBISWorld, 2020). There are about 167,746 businesses, employing approximately $1,007,320$ physicians. Nowadays, physician practice is aligning and consolidating with hospitals (IBISWorld, 2020). For instance, since 2010, most physicians have joined larger physician organizations, and more work either for organizations owned by hospitals or directly for

\section{Structure of Physician Practice Market Nationwide}

Nationwide, physician practice is a monopolistically competitive market. Essentially, monoprotic competition is an economic model presented by Edward Chamberlain in 1933. This model offers insights into the cost structure of healthcare when there is mounting concern First, this model assumes that a firm's services or products are not perfect substitutes for other firms' output in the market. Indeed, physician service's uniqueness can result from perceived differences in quality or actual differences in products (IBISWorld, 2020). The sole production of a differentiated service establishes the "monopoly" aspect. Second, according to this model, new organizations can enter heterogeneity of physicians' services.

Within this context, monopolistic competition results from an information shortage and is not based on reality (Tabarrok \& Cowen, 2015). Third, physician services are a differentiated product: even in situations with complete information, two physicians' services are not perfect substitutes for each other. Essentially, every physician has his or her interests and talents, specific ways to deal with certain diseases, diverse experiences, personal style, etc. All these features make the practice monopolistically completive in my hometown.

hospitals. While the concentration of providers can improve efficiencies that benefit patients, no evidence supports that view. For instance, according to Beveridge (2013), concentrated markets are linked to high prices, with price increases usually surpassing $20 \%$ when mergers occur. More concerning is the fact that these price increases do not improve the quality of physician services.

about runaway expenses (IBISWorld, 2020). Notably, it is well suited to explain the spread of sophisticated technologies, even when their expediency is doubtful.

the market to offer similar services if there are economic profits. In essence, free movement into the physician service market generates competitive pressures, constituting the 'competitive' aspect(Tabarrok $\&$ Cowen, 2015). Fourth, the range of service variants in the physician service market characterizes it rather than the homogeneous services assumed in perfect competition markets. 
The monopolistic competition model recognizes that market power arises from the uniqueness of products or services. The physician can increase their market share by signaling evidence of better care services. Therefore, patients are uncertain about quality and are willing to pay more for services that appear to provide a better likelihood of positive outcomes and comfort. As a result, a marketing strategy relying on indicating evidence of quality can advertise to change consumers' opinions.

Furthermore, price competition has emerged as a significant force in the physician practice sector. This changing environment partly results from increasing costs (Beveridge, 2013). Recent healthcare costs are considered excessive and have boosted the validity of growing price competition and other cost-containment measures among physicians. Anti-trust activities have significantly abridged anticompetitive behaviors by physician firms (IBISWorld, 2020). This issue has

\section{References}

1. Beveridge, T. M (2013) Chapter 8: Between perfect competition and monopoly. In A Primer on Microeconomics. New York: Business Expert Press.

2. IBISWorld (2020) Industry market research, reports, and statistics. IBISWorld - Industry Market Research, Reports, \& Statistics. effectively limited the market share of alternative health care delivery agents, controlling how physicians conduct business.

Last, there are information asymmetries in the physician service market in the United States. As suppliers, physicians know more about disease and therapies than patients. As a result, patients relyon them to act in their best interest; however, conflict of interest arises since physicians sell services to them. Thus, a physician can determine the demand for the services (acting on their patient's behalf, apparently for the patient's welfare), and a physician is also the service supplier (Tabarrok \& Cowen, 2015). therefore, both the supply and demand for physician services are mutually and simultaneously determined by the same individual(s), leading to market failure (Taylor, 2014). For instance, if a physician is driven by profits or is seeking higher income, the physician can prescribe more services or products than required.

3. Tabarrok, A, Cowen, T. [Marginal Revolution University]. (2015, January 2). Introduction to the competitive firm [Video].

4. Taylor T (2014) Monopolistic competition and oligopoly. In Principles of Microeconomics. OpenStax College. 